\title{
Analysing adventure: a leisure lifepsychle?
}

Ralf C. Buckley, International Chair in Ecotourism Research, Griffith University, Australia 4222

\section{Summary}

Adventure is an industry, an attitude, an addiction, a behaviour, a therapy. Adoption of adventure differs between individuals, activities, and life stages. I propose that we could analyse trajectories through time, in the social, physical and mental contexts for individual adventure participation, a "leisure-lifepsychle" approach.

\section{Introduction}

Businesses are built on human behaviours, and adventure is one of these. Human behaviour and life histories include leisure as well as toil. Especially in wealthier and more urbanised societies, work is boring and leisure is pleasure. For an increasing proportion of our populations, leisure includes adventure. Adventure is commonly active, outdoors, challenging, physically skilled, non-hierarchical, socially supporting, and confers individual self esteem. All these aspects contrast strongly with most urban workplaces.

More and more people in urban societies are finding that at least a modicum of adventure provides balance and purpose to life, and improves their health and happiness (Brymer and Schweitzer, 2013; Buckley and Brough 2017; Buckley, Westaway and Brough 2016; Yeh et al., 2016). So as wealthier societies have become more and more urbanised, and leisure more and more divided from work, adventure has become a more and more important component in human civilisations (Anon 2017). It deserves greater research attention, therefore, not only as a commercial enterprise and an aspect of individual behaviour, but as part of the fabric of our society. Here, therefore, I address some of the key aspects of adventure in a leisure research context.

\section{Concepts of Adventurousness}

What is adventure, exactly? Is it a mindset or a psychological state? (Brymer and Schweitzer 2017). A type of experience, memorable and educational? An activity involving challenge, thrill, fear, risk, or unknown outcomes? (Buckley 2012, 2016; Ewert et al. 2013; Kerr and Mackenzie 2012; Lee and Tseng 2015; Lynch and Dibben 2016; Tsaur and Lin 2013). An unplanned situation, or one where plans have gone awry? An industry, part of the commercial sport, tourism and recreation sector? Or perhaps, any and all of the above, depending on context and interest?

Different researchers have used widely different definitions and criteria (Buckley 2012; Rantala, Rokenes and Valkonen 2016). Considering their various approaches jointly, we can distinguish a scale or continuum from less to more adventurous, and from "high-volume, lowdifficulty, experts-in-charge" tour products, to "skilled icon adventurers" (Rantala, Rokenes and Valkonen 2016).

Perhaps we could gain further insight into this issue by asking an apparently simple question. Is adventure, or more particularly, adventurousness, defined by each individual in their own terms, or is it defined at a broad social level? Is it up to you or I individually to 
decide if our own activities are adventurous? Or, can you judge the adventurousness of my activities, and vice versa, on the basis of your expertise and experience, irrespective of mine? Or, do each of us judge ourselves and others against group norms, set by communication of exploits amongst practitioners worldwide? The answer would seem to be, all of the above.

Norms do indeed exist, based on past achievements by many practitioners. Climbing routes and whitewater rapids, for example, are assigned grades that are largely agreed amongst practitioners. Specific manoeuvres in surfing, snowboarding, skiing and skateboarding are assigned consistent scores, in freestyle competition, for degree of difficulty. Aficionados of individual activities agree in recognition of new extreme achievements, whether in technical difficulty or in speed. Athletes are celebrated for surfing ever more difficult and dangerous waves, skiing ever more difficult and dangerous descents, climbing ever more difficult and dangerous routes, kayaking ever more difficult and dangerous rapids, and doing all these things faster than ever before (Grey, 2017; Jornet, 2017; Synnott, 2017).

At the same time, we recognise that different individuals have widely different skills and expertise, and different attitudes to risk (Lepp and Herpy, 2015). What is all in a day's work to an adventure guide may be a lifetime experience for a novice client (Evans and Anderson 2016; Mackenzie and Kerr 2013). Adventurousness differs between individuals. It can also differ between activities, for the same individual. And it can change over time, for the same individual and the same activity (Lovelock et al. 2016; Widmer, Duerden and Tamiguchi 2014). This can happen for many different reasons: skills are learned or lost; opportunities are modified by changes in free time, funds, or geographical location; and attitudes to risk are altered by other life events, such as becoming a parent, starting or ending a relationship, or losing a friend.

For any individual, therefore, perhaps we could describe a lifetime trajectory of adventurousness, with: multiple threads for different activities; peaks and troughs for major life events; and an overall trend over time. The shape of that trend merits more attention. Is it an inverse $\mathrm{U}$, as one gradually acquires skills and confidence, and then gradually loses them? Is it a left-leaning sawtooth, highly adventurous in teenage years and decreasing steadily thereafter? Or is it a right-leaning sawtooth, a lifetime growth in capability and opportunity, ending only with sudden and major loss of ability in old age? The serious-leisure model would seem to imply the last of these, but perhaps that applies only to a limited number of individuals. This seems to be a worthwhile topic for future research.

Concepts of adventurousness are embedded in culture. Most previous research is on individuals from wealthier Western nations, principally English-speaking. There may be substantial differences in other cultures (Buckley et al. 2014; Buckley, Guitart and Shakeela 2017; Mackenzie and Kerr 2013; Ooko, Muthomi and Odhiambo 2015). This topic also deserves further attention.

\section{Value and Seriousness}

Some people value adventure much more than others (Chandel and Bansal 2014). For some, their chosen adventure activities are key to defining their lifestyle, self-image, and selfesteem, and represent a major priority for allocation of discretionary time and resources. For others, none of these apply. But people change, either through internal development or external events. Individuals who were dissatisfied with their life circumstances have found 
that adventure activities can change their lifestyle and attitudes (Westaway, 2017). That is, the value ascribed to adventure by individuals may change over the course of their lives.

It is this implicit valuation that drives adoption of serious leisure approaches. Individuals build a leisure career, where they spend time and money for social and psychological reward, in parallel to their work career where they trade time and expertise for financial reward (Davies 2016; Veal 2017). There is thus a kind of transfer value, from time spent and money earned at work, to time and money allocated to reward through leisure. This transfer value also differs between individuals, depending on their lifestyle strategy. There are backpackerstyle adventure tourists, who are time-rich, cash-poor; and wealthy clients of commercial adventure tour operators, who are cash-rich, time-poor (Buckley, Guitart and Shakeela 2017).

Adventure practitioners with a serious-leisure mindset behave differently to those with a casual-leisure mindset (Davies 2016). The former behave more like career athletes and sportspersons, who train despite pain. Serious hikers in the UK continue to hike, rain or shine; and some serious seakayakers prefer stormy seas to calm oceans (Davies 2016). Part of this distinction is simply that they have the equipment, fitness and expertise to deal with adverse weather conditions safely and comfortably, in contrast to novices who are unskilled and poorly equipped. Of course, this factor is one of the drivers for commercial adventure tourism, where the client pays to be properly equipped by the tour operator, and safely led and taught by a guide or instructor. The psychological processes involved in a transfer from casual to serious outlook on adventurous leisure, however, deserve further research.

The valuation of adventure rewards also deserves more attention. Expert-level adventure involves long-term investment in training, practice and equipment, in order to gain a chance at what is often a very short peak experience (Buckley 2014). This implies that such peak experiences are valued very highly by the specific individuals concerned, perhaps thousands or in a few cases potentially millions of dollars per hour. For other individuals, however, these experiences are worth nothing, or less than nothing. This enormous difference between individuals, in value ascribed to the same experience, is very different to the standard economics of supply and demand, which assumes high substitutability in order to generate elasticity (Buckley 2014).

\section{Addiction and Ageing}

Why this extremely high valuation by some individuals? There may be many different rewards from adventure (Buckley 2012; Brymer and Schweitzer 2017). For the most expert practitioners, adventure is not only rewarding, but addictive (Buckley 2015, 2016). A weak addiction may be expressed simply as a desire, which makes some individuals prepared to pay more than others, for a particular experience. For a powerful addiction, however, perhaps there is no economic calculus at all: it is a physiological imperative. Few adventure aficionados lose control of their lives in the way that some substance addicts have done. But they do indeed devote their discretionary time and resources to their passion, to the exclusion of almost all else. The reward for success is that valuable.

What happens when that reward is no longer accessible, because skill and fitness decrease with age? Is there a period of denial, when the practitioner believes they are still competent? Perhaps, but adventure practitioners are adept at measuring their own skills 
against conditions and making careful judgements on risk. They can see their own skills decreasing. So then what?

There are several options. For some adventure activities, individuals can pay to take part under easier or less competitive circumstances, through commercial operators that provide exclusive access to particular sites, and take over some of the physical aspects of the activity (Kane 2013). That may buy them a few more years. They can take up a new activity, gaining a psychological reward from new achievements, even though far below their former skill level. Or, they can accept that they will simply have to take part in their same favourite long term activity, at a lower level of skill (Hickman et al. 2016; Minello and Nixon 2017; Wheaton 2017). This is hard to accept, but ultimately inevitable, unless they withdraw from that activity completely.

For many adventurous outdoor activities, numbers of participants have grown rapidly and recently, through a range of social and technological changes (Duret and Angue 2015). Even activities with a long history, such as hiking, climbing and canoeing, have evolved considerably. As a result, it is only in recent decades that urbanised societies in wealthier nations have included substantial numbers of ageing individuals for whom adventurous outdoor leisure activities represent a major component of lifestyle choice. These individuals have gained a lifetime of expertise and experience in particular outdoor recreation and leisure activities. They have retained their skills and interests, and continue to practice their preferred activities as they grow older.

This is a sufficiently novel and substantial social trend to deserve detailed analysis. Historically, climbers and canoeists who continued their activities at an advanced level into their sixties and seventies were very rare. Currently, however, they are increasingly numerous. This trend has been underrepresented in research efforts, but merits more attention.

\section{Conclusions.}

All of these suggestions can be addressed through the same model, a lifetime trajectory of physical capability and psychological adventurousness and reward. In the terminology of other lifetime trajectories, we can refer to this as a psychological or psychophysiological lifecycle. Or, dare I suggest it, a "leisure lifepsychle”. (Quick, better make that a lifepsychle@ just in case that term takes off..).

So that is my conclusion. Let us pay some research attention to the psychological changes in adventurousness, over the course of human lives. Let us look at: when and how adventure enters their lives; how it becomes important (or not), and to what degree; how it influences health and happiness; and how it changes over the course of individual lives.

These are not trivial questions. Lifestyle dissatisfaction and poor mental health in urban nations, despite high material wealth in global relative terms, impose large social and economic costs on modern societies. Including the costs of public and private antisocial behaviour, decreased workplace productivity, and paid and unpaid healthcare, these costs amount to around $10 \%$ of GDP for wealthier nations with high per capita healthcare costs (Buckley \& Brough, 2017; Buckley et al., 2016). 
Well-spent leisure provides: a therapy for psychological stress; a safety-valve to avoid antisocial behaviours; and recreation and renewal to improve work productivity. More and more individuals are choosing adventurous options for their leisure activities. Leisure researchers have the background in human behaviour and social dynamics to work out why, and with what consequences. As outline above, this endeavour is highly worthwhile, in practical as well as theoretical terms.

\section{References}

Anon. 2017. Motivations of adventure recreation pioneers - a study of Taiwanese white-water kayaking pioneers. Annals of Leisure Research (in press).

Brymer, E., \& Schweitzer, R.D. (2013). Extreme sports are good for your health: a phenomenological understanding of fear and anxiety in extreme sport. Journal of Health Psychology, 18(4), 477-487.

Brymer, E., \& Schweitzer, R. D. (2017). Evoking the ineffable: The phenomenology of extreme sports. Psychology of Consciousness: Theory, Research, and Practice, 4(1), 63.

Buckley, R.C. 2012. Rush as a key motivation in skilled adventure tourism: Resolving the risk recreation paradox. Tourism Management 33: 961-970.

Buckley, R.C. 2014. Adventure tourism as a research tool in non-tourism disciplines. Tourism Recreation Research 39: 39-49.

Buckley, R.C. 2015. Adventure thrills are addictive. Frontiers in Psychology 6: 1915.

Buckley, R.C. 2016. Nature fix: addiction to outdoor activities. Journal of Behavioural Addiction 5: 557-558.

Buckley, R.C. 2016. Qualitative analysis of emotions: fear and thrill. Frontiers in Psychology 7: 1187

Buckley, R.C. \& Brough, P. 2017. Economic value of parks via human mental health. Frontiers in Ecology \& Evolution 5: 16.

Buckley, R.C., Guitart, D. \& Shakeela, A. 2017. Contested surf tourism resources in the Maldives. Annals of Tourism Research 64: 185-199.

Buckley, R.C., McDonald, K., Duan, L., Sun, L. and Chen, LX. 2014. Chinese model for mass adventure tourism. Tourism Management 44: 5-13.

Buckley, R.C., Westaway, D. \& Brough, P. 2016. Social mechanisms to get people outdoors. Frontiers in Public Health 4: 257.

Chandel, J. K., \& Bansal, S. P. (2014). Understanding the relationships of value, satisfaction and behavioural intentions among adventure tourists. International Journal of Leisure and Tourism Marketing, 4(2), 156-171. 
Davies, N. (2016). Who walks, where and why? Practitioners' observations and perspectives on recreational walkers at UK tourist destinations. Annals of Leisure Research, ***, 1-22.

Duret, P., \& Angué, K. (2015). Two norms for innovation in outdoor sports: technical and social innovation. Loisir et Société/Society and Leisure, 38(3), 372-382.

Evans, K., \& Anderson, D. M. (2016). 'It's never turned me back': female mountain guides' constraint negotiation. Annals of Leisure Research, ***, 1-23.

Ewert, A., Gilbertson, K., Luo, Y. C., \& Voight, A. (2013). Beyond" because it's there": Motivations for pursuing adventure recreational activities. Journal of Leisure Research, 45(1), 91.

Grey, T. 2017. Mt. Robson North Face ski descent - Dylan Cunningham interview Big Lines, June 1, 2017. www.biglines.com

Hickman, M., Stokes, P., Gammon, S., Beard, C., \& Inkster, A. (2016). Moments like diamonds in space: savoring the ageing process through positive engagement with adventure sports. Annals of Leisure Research, ***, 1-19.

Jornet, K. 2017. Summits of My Life Blog, 30 May 2017. www.summitsofmylifeblog.com

Kane, M. J. (2013). New Zealand's transformed adventure: From hero myth to accessible tourism experience. Leisure Studies, 32(2), 133-151.

Kerr, J. H., \& Mackenzie, S. H. (2012). Multiple motives for participating in adventure sports. Psychology of Sport and Exercise, 13(5), 649-657.

Lee, T. H., \& Tseng, C. H. (2015). How personality and risk-taking attitude affect the behavior of adventure recreationists. Tourism Geographies, 17(3), 307-331.

Lepp, A., \& Herpy, D. (2015). Paddlers' level of specialization, motivations and preferences for river management practices. Journal of Outdoor Recreation and Tourism, 12, 64-70.

Lovelock, B., Walters, T., Jellum, C., \& Thompson-Carr, A. (2016). The participation of children, adolescents, and young adults in nature-based recreation. Leisure Sciences, 38(5), 441-460.

Lynch, P., \& Dibben, M. (2016). Exploring motivations for adventure recreation events: a New Zealand study. Annals of Leisure Research, 19(1), 80-97.

Mackenzie, S. H., \& Kerr, J. H. (2013). Stress and emotions at work: An adventure tourism guide's experiences. Tourism Management, 36, 3-14.

Marques, C., Reis, E., Menezes, J., \& Salgueiro, M. D. F. (2017). Modelling preferences for nature-based recreation activities. Leisure Studies, 36(1), 89-107.

Minello, K., \& Nixon, D. (2017). 'Hope I never stop’: older men and their two-wheeled love affairs. Annals of Leisure Research, 20(1), 75-95. 
Ooko, S. W., Muthomi, H., \& Odhiambo, G. (2015). Impact of outdoor adventure education on Kenyan youth, in peace building. World Leisure Journal, 57(4), 297-305.

Rantala, O., Rokenes, A., \& Valkonen, J. (2016). Is adventure tourism a coherent concept? A review of research approaches on adventure tourism. Annals of Leisure Research, ***, 1-14.

Synott, M.M. 2017. Exclusive: climber completes the most dangerous rope-free ascent ever. National Geographic, 3 June 2017.

Tsaur, S. H., Lin, W. R., \& Liu, J. S. (2013). Sources of challenge for adventure tourists: Scale development and validation. Tourism Management, 38, 85-93.

Veal, A. J. (2017). The serious leisure perspective and the experience of leisure. Leisure Sciences, 39(3), 205-223.

Westaway, D. 2017. Natural Exhilaration. Self-published, Sydney. ISBN 9780995402010.

Wheaton, B. (2017). Surfing through the life-course: silver surfers' negotiation of ageing. Annals of Leisure Research, 20(1), 96-116.

Widmer, M. A., Duerden, M. D., \& Taniguchi, S. T. (2014). Increasing and generalizing selfefficacy: the effects of adventure recreation on the academic efficacy of early adolescents. Journal of Leisure Research, 46(2), 165.

Yeh, H. P., Stone, J. A., Churchill, S. M., Wheat, J. S., Brymer, E., \& Davids, K. (2016). Physical, psychological and emotional benefits of green physical activity: an ecological dynamics perspective. Sports Medicine, 46(7), 947-953. 